\title{
Robot-Assisted, Laparoscopic, and Open Radical Cystectomy (RC): Pre-Operative Data of 1400 Patients From The Italian Radical Cystectomy Registry (RIC)
}

\section{Angelo Porreca}

Oncology Institute of Veneto (IOV)

Gian Maria Busetto ( $\square$ gianmaria.busetto@unifg.it )

University of Foggia

Michele Colicchia

Policlinico Abano Terme

Katie Palmer

Catholic University of the Sacred Heart

Walter Artibani

Policlinico Abano Terme

Alessandro Antonelli

University of Verona

Lorenzo Bianchi

University of Bologna

Aldo Bocciardi

Ospedale Niguarda Ca' Granda

\section{Eugenio Brunocilla}

University of Bologna

Marco Carini

University of Florence

Giuseppe Carrieri

University of Foggia

Luigi Cormio

University of Foggia

Ugo Giovanni Falagario

University of Foggia

Ettore De Berardinis

Sapienza University of Rome

Alessandro Sciarra

Sapienza University of Rome 
Costantino Leonardo

Sapienza University of Rome

Francesco Del Giudice

Sapienza University of Rome

Martina Maggi

Sapienza University of Rome

Ottavio de Cobelli

European Institute of Oncology

Matteo Ferro

European Institute of Oncology

Gennaro Musi

European Institute of Oncology

Amelio Ercolino

University of Bologna

Fabrizio Di Maida

University of Florence

Andrea Gallina

Vita-Salute San Raffaele University

Carlo Introini

University of Genoa

Ettore Mearini

University of Perugia

Giovanni Cochetti

University of Perugia

Andrea Minervini

University of Florence

Francesco Montorsi

Vita-Salute San Raffaele University

Riccardo Schiavina

University of Bologna

Sergio Serni

University of Florence

Claudio Simeone

University of Brescia

Paolo Parma

ASST Mantova

Armando Serao

Azienda Sanitaria Locale Alessandria

Mario Salvatore Mangano 
Ca' Foncello Hospital

\section{Giorgio Pomara}

Azienda Ospedaliera Universitaria Pisana

\section{Pasquale Ditonno}

University of Bari Aldo Moro

\section{Alchiede Simonato}

University of Palermo

\section{Daniele Romagnoli}

Policlinico Abano Terme

\section{Alessandro Crestani}

Oncology Institute of Veneto (IOV)

\section{Daniele D'Agostino}

Policlinico Abano Terme

\section{Research Article}

Keywords: Urinary bladder neoplasms, Radical Cystectomy, multicenter, Italy

Posted Date: May 7th, 2021

DOl: https://doi.org/10.21203/rs.3.rs-449403/v1

License: (c) (i) This work is licensed under a Creative Commons Attribution 4.0 International License. Read Full License 


\section{Abstract}

Introduction: the Italian Radical Cystectomy Registry (RIC) is an observational prospective study aiming to understand clinical variables and patient characteristics associated with short- and long-term outcomes among bladder cancer (BC) patients undergoing radical cystectomy (RC). Moreover, it compares the effectiveness of three RC techniques - open, robotic, and laparoscopic.

Methods: from 2017 to 2020,1400 patients were enrolled at one of the 28 centers across Italy. Patient characteristics, as well as preoperative, postoperative, and follow-up $(3,6,12$, and 24 months) clinical variables and outcomes were collected.

Results: preoperatively, it was found that patients undergoing robotic procedures were younger $(\mathrm{p}<.001)$ and more likely to have undergone preoperative neoadjuvant chemotherapy $(p<.001)$ and BCG instillation $(p<.001)$. Hypertension was the most common comorbidity among all patients $(55 \%)$, and overall, patients undergoing open and laparoscopic RC had a higher Charlson Comorbidities Index (CCI) compared to robotic RC ( $\mathrm{p}$ <.001). Finally, laparoscopic patients had a lower $\mathrm{G}$-stage classification $(p=.003)$ and open patients had a higher ASA score $(p<.001)$.

Conclusion: the present study summarizes the characteristic of patients included in the RIC. Future results will provide invaluable information about outcomes among BC patients undergoing RC. This will inform physicians about the best techniques and course of care based on patient clinical factors and characteristics.

\section{Introduction}

Bladder cancer (BC) is the ninth most common type of cancer worldwide, and is sixth in Europe, with an age-standardized incidence of 17.7 per 100,000 and mortality rate of 5.2 per 100,000 among European men $(1,2)$. BC is three times more prevalent in men than women (2), and although prevalence has remained unchanged among men, incidence is increasing among women (1). Tumor stage is the factor most strongly predictive of outcomes $(3,4)$. However, little else is known about what factors may be associated with survival and health-related outcomes among BC patients. The pathophysiology behind the aggressivity of high-risk BC has not yet been fully elucidated. Poor clinical response of some patients it can be caused by disease spread, understaging or to an inherent biological aggressiveness of the tumor (5-6). Identification of new imaging strategies and prognostic biomarkers could better guide therapeutic options and identification of the molecular background of BC has improved our knowledge (tumor suppressor genes, oncogenes, cell cycle regulators, growth factors and receptors, and cell adhesion molecules) (7-8).

While recent large cohort studies have indicated that prevention of $\mathrm{BC}$ or prevention of advanced stages is the most effective way to reduce disease related morbidity and mortality, it remains that curative responses are necessary (9). Radical cystectomy (RC) is the only curative intervention available for BC. It is a highly complex procedure, needing an experienced surgeon and centralization of care to enhance 
patient outcomes $(10-13)$. Indeed, $13-67 \%$ of patients undergoing RC develop some type of complication (14-18), and while these rates of complications are high, they are also exceedingly variable.

Three techniques - open, robotic-assisted, and laparoscopic - can be used to complete RC. Roboticassisted surgery is comparable to laparoscopic, and both seem to have better outcomes than open (19). A recent meta-analysis showed that open and robotic cystectomy have similar outcomes with regard to time to recurrence, positive margins, major complication rates, and quality of life; however, it seems that a robotic approach reduces the risk of the need of blood transfusions and may reduce hospital stay (20). Even so, as of 2013 , only one-quarter of RCs were being performed robotically in the US (21). More studies, comparing RC techniques, as well as investigating what factors are associated with improved outcomes among patients are needed to (1) understand true rates of complications among patients; (2) determine what clinical factors and patient characteristics are associated with complications; and (3) determine which technique - open, robotic-assisted, or laparoscopic - is the most effective. Currently, one randomized comparative effectiveness trial is underway to help determine the answers to these questions (22). However, these questions can also be effectively addressed via large, representative cohort studies. To that end, we have designed a multicenter study aimed at addressing these gaps in the current clinical knowledge.

\section{Material And Methods}

\section{Study Design and Inclusion Criteria}

The Italian Radical Cystectomy Registry (RIC) is an observational, prospective, multicenter, cohort study, assessing patients affected by bladder neoplasms undergoing radical cystectomy and urinary diversion via open, laparoscopic, or robotic-assisted technique (23). Both male and female consecutive patients are enrolled. Additionally, patients must be $\geq 18$ years old and have histologically confirmed diagnosis of bladder cancer eligible for radical cystectomy surgery (according to EAU guidelines) at enrollment. Enrollment was planned to occur from January $1^{\text {st }} 2017$ to June $30^{\text {th }} 2020$, with a goal of enrolling 1000 patients, based on power calculations.

$\mathrm{RIC}$ is an electronic registry, and data is collected from patients at one of the 28 participating clinical centers (Table 1). At each center, patient data is collected in accordance with Italian privacy laws, and entered into an online database by a coordinating physician. Data collection and entering was done using the Data Collection Form, which was designed by the Scientific and Steering Committees. The Data collection form was designed using either pre-specified or open-ended responses for each question, to ensure homogeneity between centers.

Patient data are securely stored and kept anonymous using identification codes. The database is password protected. As data sharing is becoming increasingly important, the data is regularly transferred to a globally-accessible online platform. The trial has been registered retrospectively on ClinicalTrials.gov on 14/01/2020 with reference number NCT04228198. Data collection is conducted in accordance with 
the World Medical AssociationDeclaration of Helsinki. This study was approved on 25/06/2020 by Ethical Committee of the University of Padova (number: 0042389). All patients provide signed, informed consent.

\section{Participating Centers}

All clinics and hospitals in Italy that currently provide care for radical cystectomy patients using all three (open, robotic, laparoscopic) techniques included in this study were invited to participate. Participation was done on a voluntary basis, without additional funding for the centers or participants. A physician at each center was assigned the role of managing patient recruitment, data collection, and the entering of the data into the registry, including maintaining data security and anonymity of the patients. Patients were enrolled at 28 centers across Italy: Urology Clinic, University of Bologna; Department of Urology, AOU Careggi, Florence; European Institute of Oncology Milan; San Raffaele Hospital, Milan; University Hospital of Verona; Department of Urology, Policlinico Abano Terme (PD); Department of Urology, Spedali Civili, Brescia; Department of Urology and Kidney Transplantation, University of Foggia, Foggia; Galliera Hospital, Genoa; ASST Niguarda Metropolitan Hospital, Milan; Policlinico Umberto I, Sapienza Rome University, Rome; Department of Clinical Urology, University of Perugia; Department of Clinical Urology, Pisa; Department of Clinical Urology, Palermo University, Palermo; Department of Clinical Urology, Alessandria Hospital, Alessandria; Department of Clinical Urology, ASST Mantova, Mantova; Department of Clinical Urology, ASL Abruzzo, Chieti; Department of Clinical Urology Ca Foncello Hospital, Treviso; Department of Clinical Urology II, Bari University, Bari; Department of Clinical Urology, Vittorio Emanuele Hospital, Catania; Department of Clinical Urology, Casa Sollievo della Sofferenza, San Giovanni Rotondo; Hospital Bassiano, Bassano del Grappa; Department of Clinical Urology, Hospital San Francesco ASL 3, Nuoro; Department of Clinical Urology, Portogruaro; Department of Clinical Urology, Biella Hospital, Biella; Department of Clinical Urology Chioggia Hospital; AusI Modena, Modena; Department of Urology and Kidney Transplantation, Bianchi-Melacrino-Morelli Grand Metropolitan Hospital, Reggio Calabria (Table 1).

\section{Timeline and data collection}

Patient enrollment was planned for January $1^{\text {st }} 2017$ to June $30^{\text {th }} 2020$ (Figure 1). At each center, preoperative tumor staging, grading, ASA score, comorbidities, Charlson Comorbidity Index (CCl), concomitant CIS, chemotherapy use, BCG instillation, palliative cystectomy, and patient characteristics (age, sex, etc.) were collected preoperatively. Patients were operated on using laparoscopic, robotic or open surgery technique, at the discretion of the surgeon. Postoperatively, surgery time, type of urinary diversion, conversion to open surgery, presence of bleeding, nerve sparing, and lymphadenectomy were collected. Finally, follow-up care, histology (e.g., postoperative staging and grading), short-term (<30 days) (e.g., complications, readmissions, mortality), and long-term ( $\geq 24$ months) (e.g., mortality, survival, sexual potency, continence) parameter were collected. 
Data were cleaned and checked for discrepancies by a statistician before analysis and dissemination. In the case of missing data, the physician from the respective center was contacted and asked to review medical records and data sheets for the missing information, to minimize missingness. Chi-square and ttests were used to compare categorical and continuous variables, respectively, between surgical technique groups. Statistical analyses were performed using Stata-SE 15 (StataCorp LP, College Station, TX, USA). All tests were 2-sided with a significance level set at $p<0.05$.

\section{Results}

Even if an enrollment of 1000 patients was planned, it was closed on February 2020 because enrollment numbers exceeded original estimates. A total of 1400 patients undergoing radical cystectomy and urinary diversion via open, laparoscopic, or robotic-assisted technique were included. Patient enrollment, by center and technique, is detailed in Figure 2. Patients had a mean age of 69.9 years (SD 10.0) and $18.7 \%$ were female. Hypertension (55\%), followed by anticoagulant use (35.1\%) and other pathologies (35.4\%) were the most common comorbidities. Preoperatively, nearly all (92.6\%) were classified as grade 3 and two-thirds (65.7\%) as pT2. Preoperative patient characteristics of the overall population are presented in Table 2.

In comparison of patients by surgical technique, significant differences were found. Roughly threequarters of patients ( $n=999)$ underwent open surgery, while $25.3 \%(n=354)$ underwent robotic surgery, and the remaining 3.4\% ( $n=47)$ underwent laparoscopic surgery (Table 3). Age differed significantly by group $(p<.001)$, with those undergoing robotic surgery being the youngest. Patients also varied significantly on all comorbidities (and Charlson Comorbidity Index) except TIA. Additionally, there were differences in preoperative ASA score $(p<.001)$, with a trend for open surgery patients to have a higher score. Similarly, they differed on preoperative G-stage classification $(p=.003)$, with more laparoscopic patients being classified as $\mathrm{G} 2$, versus $\mathrm{G} 3$, which was more common among open and robotic patients. Moreover, patients who underwent robotic surgery had higher rates of preoperative neoadjuvant chemotherapy $(p<.001)$ and BCG instillation ( $p<0.001)$, while open surgery patients had higher rates of palliative cystectomy $(p<.001)$. Patients did not differ between groups on preoperative T-stage $(p=.128)$ or concomitant CIS $(p=.136)$

\section{Discussion}

This first study from the Italian Radical Cystectomy Registry (RIC) reported preoperative results of BC patients, comparing three RC techniques - open, robotic-assisted, and laparoscopic. This study was designed to assess, in a real-world context, factors associated with disease-related morbidity and mortality and effectiveness of the separate RC techniques. We found that among $\mathrm{BC}$ patients undergoing $\mathrm{RC}$, those undergoing robotic procedures were younger and more likely to have undergone preoperative neoadjuvant chemotherapy and BCG instillation. Additionally, patients undergoing open and laparoscopic $\mathrm{RC}$ had a higher Charlson Comorbidities Index compared to patient undergoing robotic $\mathrm{RC}(\mathrm{p}<.001)$. There were also significant differences in terms of grading and staging between patient groups, including 
laparoscopic patients having a lower G-stage classification and open patients having a higher ASA score. This suggests that laparoscopic patients, at least compared to open patients, have less advanced disease at the time of surgery.

In our study, BC patients undergoing robotic RC were younger. Conversely, Rai et al., in a Cochrane Review comparing robotic versus open radical cystectomy, showed no differences in patients age between robotic and open group (20).

These preliminary findings from this large prospective cohort study suggest that differences observed in disease-related morbidity and mortality between RC techniques may be related to preoperative patient clinical factors and characteristics. Although past studies have suggested that outcomes are similar among patient who undergo robotic and laparoscopic RC, some of these differences may be due to preoperative differences between groups $(19,20)$. Currently, one study is attempting to disentangle what may be due to inherent differences versus technique in a randomized comparative effectiveness trial (22). However, it must be noted that surgeons must evaluate the safest and most effective technique for the patient based on a myriad of real-world factors. Although trending evidence suggests that robotic or laparoscopic surgery is preferable to open surgery, only $25 \%$ of $B C$ patients undergo robotic surgery in the US (21), which is consistent with our findings. Therefore, understanding why most surgeries are still being done using an open technique and how this may affect patients is critical to improving outcomes.

This study has a number of strengths, including a large, representative sample, a longitudinal design, and a real-world contextual setting. However, we must also consider that there are surgeon biases that may affect technique choice, which cannot be controlled. Additionally, although this sample is representative of southern Europe, the highest BC incidence and mortality rates are in high human development index countries (1), so findings from this study and future studies in the RIC may not be generalizable to these populations. Finally, because laparoscopic procedures are still uncommon, there were few patients (3.4\%) in our cohort who underwent this type of intervention. Therefore, power may have been and may be limited in analyzing results in this group. However, this study was designed to have sufficient power and, indeed, exceeded enrollment targets.

\section{Conclusion}

This study presented preliminary, preoperative results from RIC. RIC is a prospective longitudinal study that will follow patients postoperatively and over the follow-up care period. As the study progresses, we will be able to investigate clinical factors and patient characteristics associated with both short- and longterm outcomes, as well as differences in outcomes based on technique used. This study will provide invaluable information that will help to inform physicians about the best care plans for BC patients to reduce disease-related morbidity and mortality.

\section{Declarations}




\section{Data Availability}

The datasets used and analyzed during the current study are available from the corresponding author on reasonable request.

\section{Statement of Ethics}

Data collection were conducted in accordance with the World Medical Association Declaration of Helsinki. All potential participants were required to sign an Informed Consent form. Ethical permission was received from Ethical Committee of the University of Padova (number: 0042389).

\section{Disclosure Statement}

The authors have no conflicts of interest to declare.

\section{Funding Sources}

The Italian Radical Cystectomy Registry is an observational, non-profit study. AB Medica provided an unconditional grant for the maintenance of the database. AB Medica has no involvement in the acquisition, control, or management of the data. The registry and all data are exclusively owned by the Steering Committee.

\section{Authors' contributions}

$A A, A B, R S, L C, A M$ are on the Scientific Committee for the current project. WA and AP are on the steering committee for the current project. AP, WA, AA, LB, LC, AB, EB, MCa, GCa, GMB, EDB, ASc, CL, ODC, MF, GM, $A E, F D M, A G, C l, E M, G C o, A M, F M, R S, S S, C S, D R, A C, P P, P D, A S e, A S i, M S M, G P$ and DDA provided patient data for the multicenter trial described in the article. All authors provided input into the planning of the protocol including definition of inclusion criteria, variables and data collection. MCo, FDG, MM, GMB, UGF, KP and GMB wrote the manuscript draft. All authors revised the draft.

\section{Acknowledgments}

Appreciation for contribution and data collection is expressed to Gianluca D'Elia (Roma), Stefano Zaramella (Biella), Salvatore Bartolotta (Catania), Mario Falsaperla (Catania), Antonio Cisternino (San Giovanni Rotondo), Tommaso Cai (Trento), Pietro Cozzupuoli (Reggio Calabria), Luca Cindolo (Roma), Francesco Beniamin (Treviso), Carlo Alberto Sepich (Versilia), Vincenzo De Marco (Verona), Alessandro Mastrorosa (Bari), Giancarlo Peracchia (Modena), Vito Mancini (Foggia), Alberto Abrate (Palermo), Silvia Secco (Milano), Massimiliano Chessa (Nuoro), Mauro Gacci (Firenze), Grazino Vignoli (Firenze), Riccardo Campi (Firenze), Sandro Benvenuti (Aosta), Alessandro Terrin (Chioggia), Bernardi Diego (Cuneo), Filippo Annino (San Donato di Arezzo), Michele Amenta (Portogruaro).

\section{References}


1. Antoni S, Ferlay J, Soerjomataram I, Znaor A, Jemal A, Bray F. Bladder Cancer Incidence and Mortality: A Global Overview and Recent Trends. Vol. 71, European Urology. Elsevier B.V.; 2017. p. 96-108.

2. Leal J, Luengo-Fernandez R, Sullivan R, Witjes JA. Economic Burden of Bladder Cancer Across the European Union. Eur Urol. 2016 Mar 1;69(3):438-47.

3. Bochner BH, Dalbagni G, Kattan MW, Fearn P, Vora K, Hee SS, et al. Postoperative nomogram predicting risk of recurrence after radical cystectomy for bladder cancer. J Clin Oncol. 2006;24(24):3967-72.

4. Hautmann RE, De Petriconi RC, Pfeiffer C, Volkmer BG. Radical cystectomy for urothelial carcinoma of the bladder without neoadjuvant or adjuvant therapy: Long-term results in 1100 patients. Eur Urol. 2012;61(5):1039-47.

5. Nicolazzo C, Busetto GM, Gradilone A, Sperduti I, Del Giudice F, et al. Circulating Tumor Cells Identify Patients with Super-High-Risk Non-Muscle-Invasive Bladder Cancer: Updated Outcome Analysis of a Prospective Single-Center Trial. Oncologist. 2019 May;24(5):612-616.

6. Nicolazzo C, Busetto GM, Del Giudice F, Sperduti I, Giannarelli D, et al. The long-term prognostic value of survivin expressing circulating tumor cells in patients with high-risk non-muscle invasive bladder cancer (NMIBC). J Cancer Res Clin Oncol. 2017 Oct;143(10):1971-1976.

7. Del Giudice F, Leonardo C, Simone G, Pecoraro M, De Berardinis E, et al. Preoperative detection of Vesical Imaging-Reporting and Data System (VI-RADS) score 5 reliably identifies extravesical extension of urothelial carcinoma of the urinary bladder and predicts significant delayed time to cystectomy: time to reconsider the need for primary deep transurethral resection of bladder tumour in cases of locally advanced disease? BJU Int. 2020 Nov;126(5):610-619.

8. Ferro M, La Civita E, Liotti A, Cennamo M, Tortora F, et al. Liquid Biopsy Biomarkers in Urine: A Route towards Molecular Diagnosis and Personalized Medicine of Bladder Cancer. J Pers Med. 2021 Mar 23;11(3):237.

9. Schulz GB, Grimm T, Buchner A, Jokisch F, Kretschmer A, Stief CG, et al. Bladder Cancer Stage Development, 2004-2014 in Europe Compared With the United States: Analysis of European Population-based Cancer Registries, the United States SEER Database, and a Large Tertiary Institutional Cohort. Clin Genitourin Cancer. 2020;2004-14.

10. Mayer EK, Purkayastha S, Athanasiou T, Darzi A, Vale JA. Assessing the quality of the volumeoutcome relationship in uro-oncology. BJU Int. 2009 Feb 1;103(3):341-9.

11. Scarberry K, D M, Berger NG, D M, Scarberry KB, S B, et al. Improved surgical outcomes following radical cystectomy at high-volume centers in fl uence overall survival. Urol Oncol Semin Orig Investig. 2018;c:1-7.

12. Grande P, Campi R, Rouprêt M. Relationship of surgeon/hospital volume with outcomes in urooncology surgery. Curr Opin Urol. 2018;28(3):251-9.

13. Afshar M, Goodfellow H, Jackson-Spence F, Evison F, Parkin J, Bryan RT, et al. Centralisation of radical cystectomies for bladder cancer in England, a decade on from the 'Improving Outcomes 
Guidance': the case for super centralisation. BJU Int. 2018 Feb 1;121(2):217-24.

14. Novara G, Catto JWF, Wilson T, Annerstedt M, Chan K, Murphy DG, et al. Systematic review and cumulative analysis of perioperative outcomes and complications after robot-assisted radical cystectomy. In: European Urology. Elsevier B.V.; 2015. p. 376-401.

15. Musch M, Janowski M, Steves A, Roggenbuck U, Boergers A, Davoudi Y, et al. Comparison of early postoperative morbidity after robot-assisted and open radical cystectomy: Results of a prospective observational study. BJU Int. 2014;113(3):458-67.

16. Cookson MS, Dutta SC, Chang SS, Clark T, Smith JA, Wells N. Health related quality of life in patients treated with radical cystectomy and urinary diversion for urothelial carcinoma of the bladder: Development and validation of a new disease specific questionnaire. J Urol. 2003 Nov 1;170(5):1926-30.

17. Shabsigh A, Korets R, Vora KC, Brooks CM, Cronin AM, Savage C, et al. Defining Early Morbidity of Radical Cystectomy for Patients with Bladder Cancer Using a Standardized Reporting Methodology. Eur Urol. 2009;55(1):164-76.

18. Konety BR, Allareddy V, Herr H. Complications after radical cystectomy: Analysis of population-based data. Urology. 2006 Jul 1;68(1):58-64.

19. Fonseka T, Ahmed K, Froghi S, Khan SA, Dasgupta P, Shamim Khan M. Comparing robotic, laparoscopic and open cystectomy: a systematic review and meta-analysis. Arch Ital Urol Androl. 2015;87(1):41-8.

20. Rai BP, Bondad J, Vasdev N, Adshead J, Lane T, Ahmed K, et al. Robotic versus open radical cystectomy for bladder cancer in adults. BJU Int. 2019;

21. Hanna N, Leow JJ, Sun M, Friedlander DF, Seisen T, Abdollah F, et al. Comparative effectiveness of robot-assisted vs. open radical cystectomy. Urol Oncol Semin Orig Investig. 2018 Mar 1;36(3):88.e188.e9.

22. Wijburg CJ, Michels CTJ, Oddens JR, Grutters JPC, Witjes JA, Rovers MM. Robot assisted radical cystectomy versus open radical cystectomy in bladder cancer (RACE): Study protocol of a nonrandomized comparative effectiveness study. BMC Cancer. 2018;18(1):1-9.

23. Porreca A, Palmer K, Artibani W, Antonelli A, Bianchi L, et al. Protocol of the Italian Radical Cystectomy Registry (RIC): a non-randomized, 24-month, multicenter study comparing roboticassisted, laparoscopic, and open surgery for radical cystectomy in bladder cancer. BMC Cancer. 2021 Jan 11;21(1):51.

\section{Tables}

Table 1. General characteristics of the 1400 patients in the Italian Radical Cystectomy trial: number of surgical techniques used for radical cystectomy (open, robotic, laparoscopic) in 28 medical centers. 


\begin{tabular}{|c|c|c|c|c|c|c|c|c|}
\hline & \multicolumn{2}{|c|}{ Open } & \multicolumn{2}{|c|}{ Robotic } & \multicolumn{2}{|c|}{ Laparoscopic } & \multicolumn{2}{|l|}{ Total } \\
\hline & $\mathrm{n}$ & $\%$ & $\mathrm{n}$ & $\%$ & $\mathrm{n}$ & $\%$ & $\mathrm{n}$ & $\%$ \\
\hline All hospitals & 999 & 71.36 & 354 & 25.29 & 47 & 3.36 & 1400 & 100.00 \\
\hline Center \# 1 & 21 & 100.00 & 0 & 0.00 & 0 & 0.00 & 21 & 1.50 \\
\hline Center \# 2 & 32 & 100.00 & 0 & 0.00 & 0 & 0.00 & 32 & 2.29 \\
\hline Center \# 3 & 9 & 47.37 & 9 & 47.37 & 1 & 5.26 & 19 & 1.36 \\
\hline Center \# 4 & 4 & 50.00 & 3 & 37.50 & 1 & 12.50 & 8 & 0.57 \\
\hline Center \# 5 & 5 & 62.50 & 0 & 0.00 & 3 & 37.50 & 8 & 0.57 \\
\hline Center \# 6 & 162 & 95.86 & 2 & 1.18 & 5 & 2.96 & 169 & 12.07 \\
\hline Center \# 7 & 73 & 97.33 & 2 & 2.67 & 0 & 0.00 & 75 & 5.36 \\
\hline Center \# 8 & 9 & 56.25 & 0 & 0.00 & 7 & 43.75 & 16 & 1.14 \\
\hline Center \# 9 & 5 & 100.00 & 0 & 0.00 & 0 & 0.00 & 5 & 0.36 \\
\hline Center \# 10 & 107 & 63.69 & 61 & 36.31 & 0 & 0.00 & 168 & 12.00 \\
\hline Center \# 11 & 63 & 98.44 & 1 & 1.56 & 0 & 0.00 & 64 & 4.57 \\
\hline Center \# 12 & 50 & 86.21 & 0 & 0.00 & 8 & 13.79 & 58 & 4.14 \\
\hline Center \# 13 & 68 & 50.75 & 66 & 49.25 & 0 & 0.00 & 134 & 9.57 \\
\hline Center \# 14 & 105 & 66.88 & 52 & 33.12 & 0 & 0.00 & 157 & 11.21 \\
\hline Center \# 15 & 22 & 91.67 & 0 & 0.00 & 2 & 8.33 & 24 & 1.71 \\
\hline Center \# 16 & 5 & 100.00 & 0 & 0.00 & 0 & 0.00 & 5 & 0.36 \\
\hline Center \# 17 & 34 & 82.93 & 7 & 17.07 & 0 & 0.00 & 41 & 2.93 \\
\hline Center \# 18 & 10 & 100.00 & 0 & 0.00 & 0 & 0.00 & 10 & 0.71 \\
\hline Center \# 19 & 33 & 100.00 & 0 & 0.00 & 0 & 0.00 & 33 & 2.36 \\
\hline Center \# 20 & 15 & 42.86 & 20 & 57.14 & 0 & 0.00 & 35 & 2.50 \\
\hline Center \# 21 & 0 & 0.00 & 86 & 100.00 & 0 & 0.00 & 86 & 6.14 \\
\hline Center \# 22 & 10 & 100.00 & 0 & 0.00 & 0 & 0.00 & 10 & 0.71 \\
\hline Center \# 23 & 3 & 100.00 & 0 & 0.00 & 0 & 0.00 & 3 & 0.21 \\
\hline Center \# 24 & 17 & 45.95 & 0 & 0.00 & 20 & 54.05 & 37 & 2.64 \\
\hline Center \# 25 & 0 & 0.00 & 16 & 100.00 & 0 & 0.00 & 16 & 1.14 \\
\hline Center \# 26 & 20 & 100.00 & 0 & 0.00 & 0 & 0.00 & 20 & 1.43 \\
\hline
\end{tabular}




\begin{tabular}{|lllllllll|} 
Center \# 27 & 27 & 57.45 & 20 & 42.55 & 0 & 0.00 & 47 & 3.36 \\
Center \# 28 & 90 & 90.91 & 9 & 9.09 & 0 & 0.00 & 99 & 7.07 \\
\hline
\end{tabular}

Table 2. Pre-operative characteristics of all patients $(n=1400)$ 


\begin{tabular}{|c|c|c|}
\hline & Mean & $S D$ \\
\hline \multirow[t]{2}{*}{ Age } & 69.9 & 10.0 \\
\hline & $\mathbf{n}$ & $\%$ \\
\hline Female & 262 & 18.7 \\
\hline Charlson Comorbidity Index (CCl) & 3.7 & 2.5 \\
\hline Diabetes & 243 & 17.4 \\
\hline Hypertension & 770 & 55.0 \\
\hline Cardiopathy & 344 & 24.6 \\
\hline COPD & 202 & 14.4 \\
\hline TIA & 71 & 5.1 \\
\hline Anticoagulants & 492 & 35.1 \\
\hline Other pathologies & 495 & 35.4 \\
\hline \multicolumn{3}{|l|}{ ASA score (missing $n=86$ ) } \\
\hline 1 & 106 & 8.1 \\
\hline 2 & 575 & 43.8 \\
\hline 3 & 569 & 43.3 \\
\hline 4 or 5 & 64 & 4.9 \\
\hline \multicolumn{3}{|l|}{ Preoperative T-stage (missing $n=42$ ) } \\
\hline $\mathrm{Ta}$ & 50 & 3.7 \\
\hline T1 & 263 & 19.4 \\
\hline $\mathrm{T} 2$ & 892 & 65.7 \\
\hline T3 & 65 & 4.8 \\
\hline T4a & 35 & 2.6 \\
\hline $\mathrm{T} 4 \mathrm{~b}$ & 10 & 0.7 \\
\hline TIS & 43 & 3.2 \\
\hline \multicolumn{3}{|l|}{ Preoperative G-stage (missing $n=58$ ) } \\
\hline G0 (undetermined) & 14 & 1.0 \\
\hline G1 & 19 & 1.4 \\
\hline G2 & 66 & 4.9 \\
\hline
\end{tabular}




\begin{tabular}{|lcc|} 
G3 & 1243 & 92.6 \\
\hline Preoperative Concomitant CIS (missing n=42) & 216 & 15.9 \\
\hline Preoperative neoadjuvant chemotherapy (missing n=26) & 158 & 11.5 \\
\hline Preoperative BCG instillation (missing $n=28)$ & 281 & 20.5 \\
\hline Preoperative palliative cystectomy (missing $n=38)$ & 129 & 9.5 \\
\hline
\end{tabular}

Table 3. Pre-operative characteristics of patients according to surgical technique 


\begin{tabular}{|c|c|c|c|c|c|c|c|}
\hline & \multicolumn{2}{|c|}{ Open $(n=999)$} & \multicolumn{2}{|c|}{ Robotic (n=354) } & \multicolumn{2}{|c|}{$\begin{array}{l}\text { Laparoscopic } \\
(n=47)\end{array}$} & \multirow{2}{*}{$\begin{array}{l}P \\
\text { value }\end{array}$} \\
\hline & Mean/n & $S D / \%$ & Mean/n & $S D / \%$ & Mean/n & $S D / \%$ & \\
\hline \multirow[t]{2}{*}{ Age } & 71.2 & 9.5 & 65.9 & 10.1 & 71.8 & 10.0 & $<.001$ \\
\hline & $\mathrm{n}$ & $\%$ & $\mathbf{n}$ & $\%$ & $\mathrm{n}$ & $\%$ & \\
\hline Female & 204 & 20.4 & 51 & 14.4 & 7 & 14.9 & .039 \\
\hline $\begin{array}{l}\text { Charlson Comorbidity Index } \\
\text { (CCl) }\end{array}$ & 4.04 & 2.6 & 2.88 & 2.14 & 4.15 & 2.4 & $<0.001$ \\
\hline Diabetes & 184 & 18.4 & 46 & 13 & 13 & 27.7 & .011 \\
\hline Hypertension & 569 & 57 & 172 & 48.6 & 29 & 61.7 & .016 \\
\hline Cardiopathy & 272 & 27.2 & 55 & 15.5 & 17 & 36.2 & $<.001$ \\
\hline COPD & 162 & 16.2 & 32 & 9 & 8 & 17 & .004 \\
\hline TIA & 57 & 5.7 & 12 & 3.4 & 2 & 4.3 & .225 \\
\hline Anticoagulants & 372 & 37.2 & 97 & 27.4 & 23 & 48.9 & .001 \\
\hline Other pathologies & 384 & 38.4 & 87 & 24.6 & 24 & 51.1 & $<.001$ \\
\hline ASA score (missing $n=86$ ) & & & & & & & $<.001$ \\
\hline 1 & 43 & 4.5 & 61 & 20 & 2 & 4.3 & \\
\hline 2 & 391 & 40.6 & 160 & 52.5 & 24 & 51.1 & \\
\hline 3 & 471 & 49 & 81 & 26.6 & 19 & 36.2 & \\
\hline 4 or 5 & 57 & 5.9 & 3 & 1 & 4 & 8.5 & \\
\hline $\begin{array}{l}\text { Preoperative T-stage (missing } \\
n=42 \text { ) }\end{array}$ & & & & & & & .128 \\
\hline Ta & 35 & 3.6 & 14 & 4.1 & 1 & 2.2 & \\
\hline T1 & 194 & 19.9 & 58 & 17.1 & 11 & 23.9 & \\
\hline T2 & 627 & 64.4 & 237 & 69.9 & 28 & 60.9 & \\
\hline T3 & 47 & 4.8 & 14 & 4.1 & 4 & 8.7 & \\
\hline T4a & 32 & 3.3 & 2 & 0.6 & 1 & 2.2 & \\
\hline $\mathrm{T} 4 \mathrm{~b}$ & 10 & 1 & 0 & 0 & 0 & 0 & \\
\hline TIS & 28 & 2.9 & 14 & 4.1 & 1 & 2.2 & \\
\hline Preoperative G-stage (missing & & & & & & & .003 \\
\hline
\end{tabular}




\begin{tabular}{|llllllll|}
\hline $\mathrm{n}=58)$ & & & & & & & \\
\hline $\mathrm{G} 0$ (undetermined) & 9 & 0.9 & 5 & 1.5 & 0 & 0 & \\
\hline $\mathrm{G} 1$ & 17 & 1.8 & 2 & 0.6 & 0 & 0 & \\
$\mathrm{G} 2$ & 43 & 4.5 & 15 & 4.5 & 8 & 17.4 & \\
\hline $\mathrm{G} 3$ & 895 & 92.8 & 310 & 93.4 & 38 & 82.6 & \\
\hline $\begin{array}{l}\text { Preoperative Concomitant CIS } \\
\text { (missing n=42) }\end{array}$ & 150 & 15.3 & 62 & 18.6 & 4 & 8.5 & .136 \\
\hline $\begin{array}{l}\text { Preoperative neoadjuvant } \\
\text { chemotherapy (missing } \mathrm{n}=26)\end{array}$ & 88 & 8.9 & 70 & 20.6 & 0 & 0 & $<.001$ \\
\hline $\begin{array}{l}\text { Preoperative BCG instillation } \\
\text { (missing n=28) }\end{array}$ & 182 & 18.4 & 95 & 28.3 & 4 & 8.5 & $<.001$ \\
\hline $\begin{array}{l}\text { Palliative cystectomy (missing } \\
\mathrm{n}=38 \text { ) }\end{array}$ & 109 & 11.1 & 12 & 3.6 & 8 & 17 & $<.001$ \\
\hline
\end{tabular}

Figures 


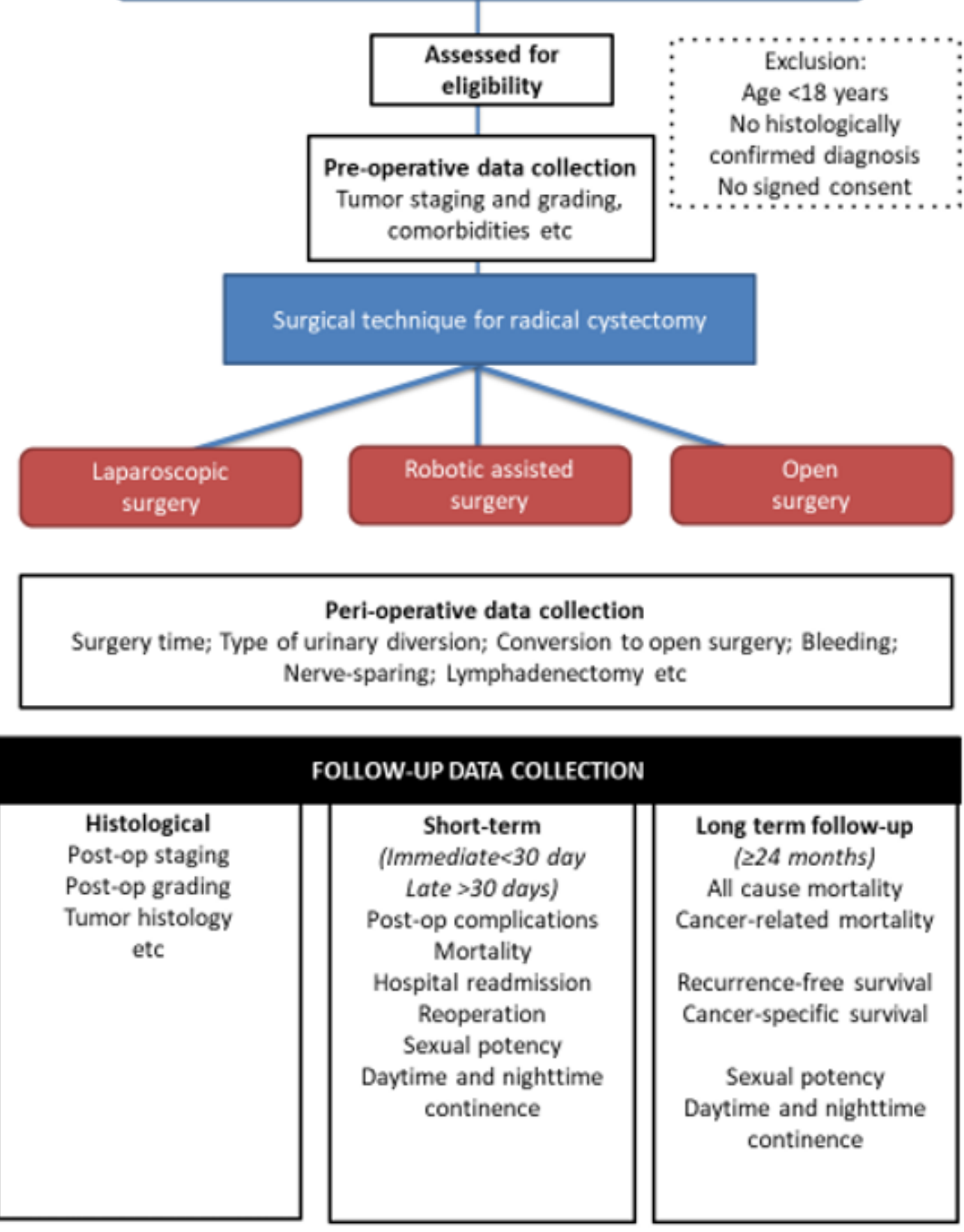

Figure 1

Study phases and summary of key data. 


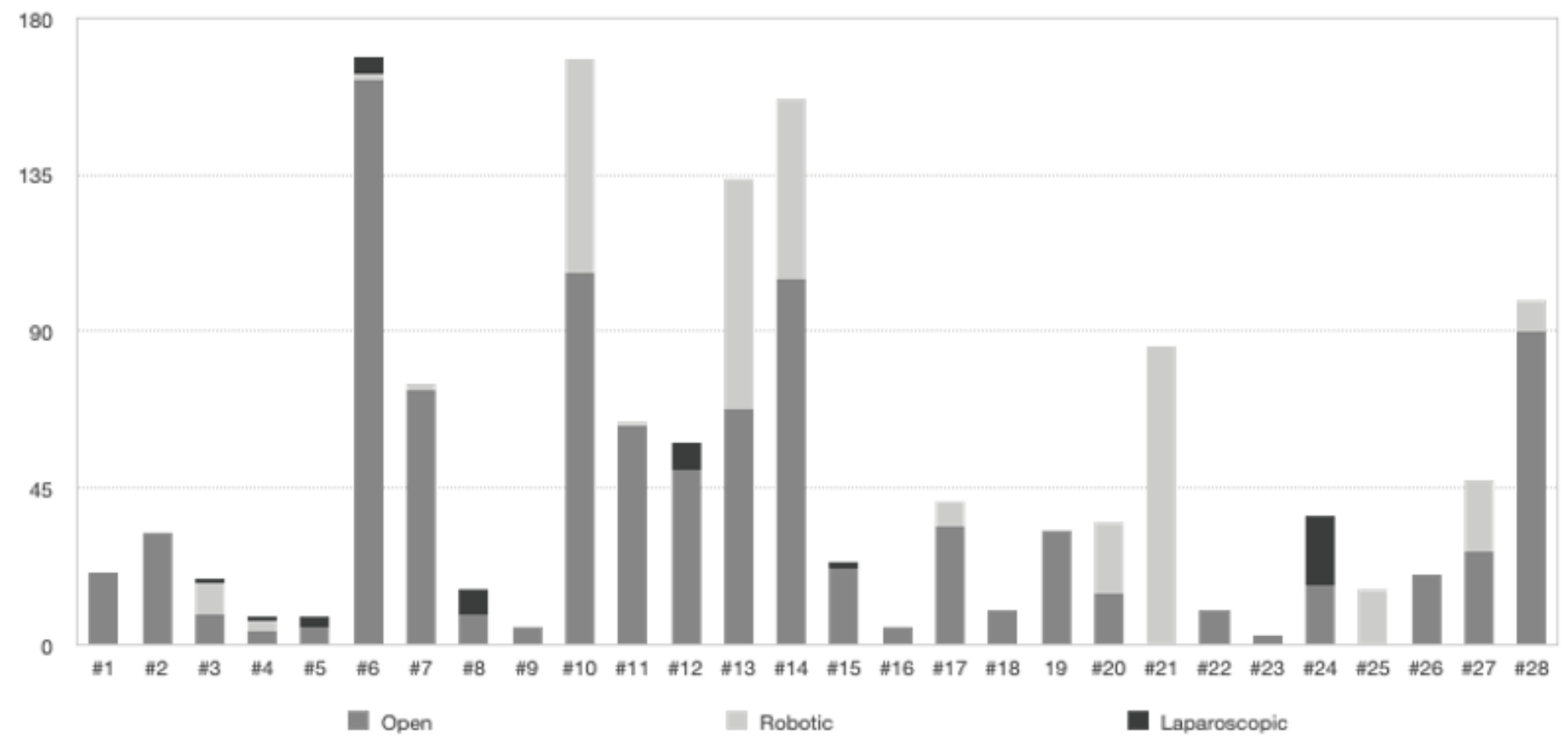

Figure 2

Case volume of RC in the Italian Radical Cystectomy trial in 28 medical centers. 